\title{
Coupling caspase cleavage and ubiquitin-proteasome-dependent degradation of SSRP1 during apoptosis
}

\author{
I Landais ${ }^{1}$, $\mathrm{H}$ Lee $^{1}$ and $\mathrm{H} \mathrm{Lu}{ }^{*, 1}$ \\ ${ }^{1}$ Department of Biochemistry and Molecular Biology, Oregon Health \\ and Science University, Portland, OR, USA \\ * Corresponding author: H Lu, Department of Biochemistry and Molecular \\ Biology, Oregon Health \& Science University, 3181 SW Sam Jackson Park \\ Road, Portland, OR 97239, USA. Tel: + 1503494 7414; \\ Fax: + 1503494 8393; E-mail: luh@ohsu.edu
}

Received 05.8.05; revised 22.12.05; accepted 23.12.05; published online 24.2.06 Edited by BD Dynlacht

\begin{abstract}
Structure-specific recognition protein (SSRP1) is an $87 \mathrm{kDa}$ protein that heterodimerizes with Spt16 to form FACT, a complex initially shown to facilitate chromatin transcription. Despite its crucial roles in transcription and replication, little is known about the dynamics of FACT turnover in vivo. Here, we show that SSRP1 is cleaved during apoptosis by caspase 3 and/or 7 at the $D^{2}$ HD $_{450}$ site. Analysis of the resulting fragments suggests that cleavage of SSRP1 generates a truncated, chromatin-associated form of FACT. Furthermore, the N-terminal product is stabilized by proteasome inhibitors and ubiquitylated in cells, suggesting degradation through the ubiquitin-proteasome pathway. These results demonstrate that SSRP1 degradation during apoptosis is a two-step process coupling caspase cleavage and ubiquitin-dependent proteolysis.

Cell Death and Differentiation (2006) 13, 1866-1878. doi:10.1038/sj.cdd.4401878; published online 24 February 2006
\end{abstract}

Keywords: chromatin; FACT; proteasome inhibitor; MG132

Abbreviations: 6-AU, 6-azauracil; $\mathrm{CHX}$, cycloheximide; $\mathrm{CK}$, casein kinase 2; FACS, fluorescence-activated cell sorting; FACT, facilitates chromatin transcription; HMG, high-mobility group; I $\overline{\mathrm{B}}$, immunoblot; RIPA, radio-immunoprecipitation assay; SRF, serum response factor; SSRP1, structure-specific recognition protein; TNF- $\alpha$, tumor necrosis factor- $\alpha$; UVC, ultraviolet C; wt, wild type

\section{Introduction}

In eucaryotic cells, chromatin has progressively emerged as a key component of major cellular processes involving genomic DNA, including transcription, ${ }^{1}$ replication ${ }^{2}$ and DNA repair. ${ }^{3}$ In chromatin, DNA tightly wraps around histone octamers to form nucleosomes, ${ }^{4}$ compromising its accessibility to multiprotein complexes such as DNA and RNA polymerases. Chromatin is therefore a repressive structure that requires remodeling prior to DNA transcription, replication or repair. A nucleosomal complex called FACT (facilitates chromatin transcription) has been identified as a key factor for transcriptional elongation. ${ }^{5}$ Human FACT promotes nucleosome disassembly in vitro by selectively removing one histone H2A-H2B dimer. ${ }^{6,7}$ Interestingly, FACT appears to reassemble nucleosomes after the passage of the RNA polymerase II, reconstituting the repressive state of chromatin. ${ }^{6}$ Remarkably, ATP is not required, suggesting that the mechanism by which FACT remodels nucleosomes differs fundamentally from other chromatin remodeling factors such as SWI/SNF. ${ }^{8}$ In yeast and xenopus, FACT is directly involved in DNA replication. ${ }^{9-11}$ Fewer studies have explored the role of FACT in recombination ${ }^{12}$ and DNA-damage response. Our lab recently showed that ultraviolet (UV) irradiation causes human FACT to associate with casein kinase 2, which results in the DNA-damage-dependent phosphorylation and activation of $p 53 .{ }^{13,14}$

The FACT complex is a heterodimeric structure composed of Spt16 and structure-specific recognition protein (SSRP1), both proteins evolutionarily conserved in eucaryotes. Spt16 $(140 \mathrm{kDa})$ was first identified in yeast by its ability to rescue transcriptional defects caused by the insertion of the transposon $\gamma$ in HIS4 and LYS2 genes. ${ }^{15}$ SSRP1 is an $87 \mathrm{kDa}$, high-mobility group (HMG)-1-containing protein that binds both cisplatin-modified DNA ${ }^{16}$ and native DNA nonspecifically. ${ }^{17}$ In yeast, SSRP1 function is fulfilled by two proteins called Pob3 and Nhp6. ${ }^{18}$ Pob3 corresponds to the first $2 / 3$ of SSRP1, whereas Nhp6 is composed of the C-terminal HMG-1 domain (Figure 1C). SSRP1 may also have Spt16-independent roles in mammalian cells. It is involved in the activation of the $\beta$-globin promoter, ${ }^{19}$ and has been identified as a coactivator of transcription factors serum response factor $(\mathrm{SRF})^{20}$ and $\mathrm{p} 63 .{ }^{21}$

Although nuclear functions of FACT are well documented, little is known about the regulation of the complex. Recent works suggest that SSRP1 phosphorylation by casein kinase 2 (CK2) alters its DNA-binding properties. ${ }^{22,23}$ During our studies attempting to understand the significance of this post-translational modification, we observed a reproducible decrease of SSRP1 levels after UV treatment. This prompted us to study SSRP1 turnover and elucidate the mechanism of SSRP1 degradation. Our findings suggest that SSRP1 is specifically cleaved during apoptotic cell death and that the resulting $\mathrm{N}$-terminal fragment is further degraded through the ubiquitin-proteasome pathway.

\section{Results}

\section{SSRP1 is stable in growing cells but disappears upon apoptosis induction}

To measure the half-life of SSRP1, human cell lines $(\mathrm{H} 1299$, small-cell lung carcinoma; MCF7, breast cancer; U2OS, 
a

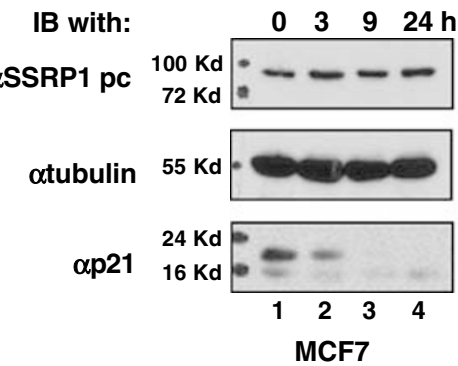

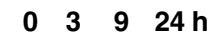

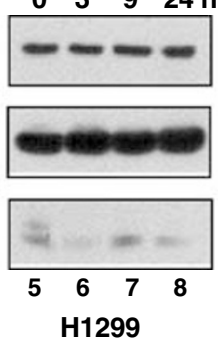

$\begin{array}{llll}0 & 3 & 9 & 24 \\ \text { hrs CHX }\end{array}$

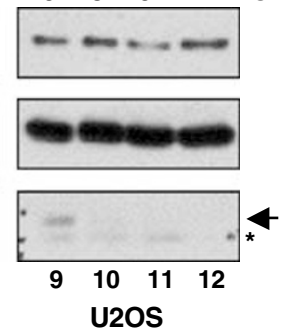

b

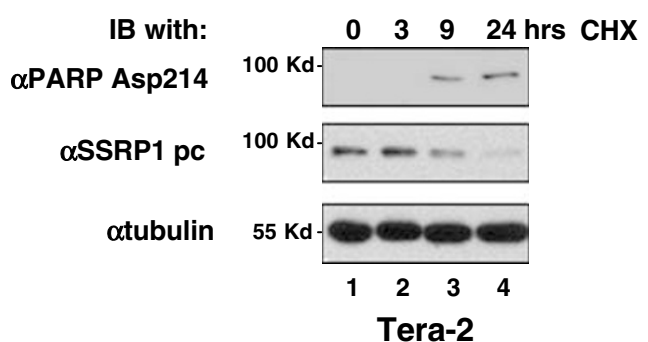

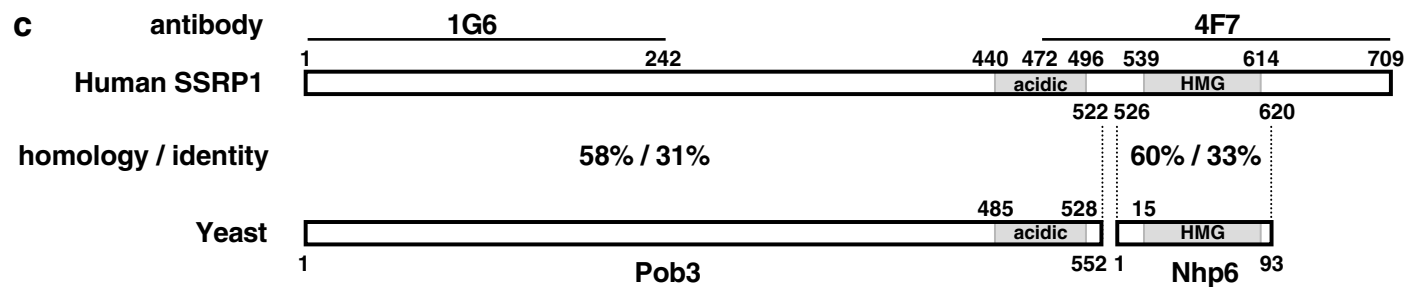

Figure 1 SSRP1 is stable in growing cells but disappears upon apoptosis. (a) SSRP1 half-life assay in three cell lines. Cells were treated with $50 \mu \mathrm{g} / \mathrm{ml}$ cycloheximide (CHX) and harvested at the indicated times. In total, $30 \mu \mathrm{g}$ of total proteins was analyzed by immunoblot (IB) using a polyclonal SSRP1 antibody (top panel). Equal loading was demonstrated on the same blot using tubulin- $\alpha$ (middle panel), while the degradation of p21 (bottom panel, bold arrow) was monitored as a positive control of $\mathrm{CHX}$ treatment. As in next figures, stars indicate nonspecific bands. (b) SSRP1 disappears following CHX -induced apoptosis in Tera-2 cells. The same experiment as in (a) was performed on Tera-2 cells. The PARP $89 \mathrm{kDa}$ cleavage fragment monitored the apoptotic status of the cells. (c) Schematic alignment of human SSRP1 with yeast Pob3 and Nhp6. The acidic and HMG-1 domains are boxed in gray. Numbers above and below the schematic correspond to amino-acid positions. Percentage of homology and identity between human and yeast amino-acid sequences are indicated. Approximate locations of the epitopes for the monoclonal 1G6 and 4F7 SSRP1 antibodies are indicated above the schematic

osteosarcoma) were treated with the translation inhibitor cycloheximide $(\mathrm{CHX})$ and harvested at various times posttreatment. Immunoblot showed no detectable decrease of SSRP1 even after $24 \mathrm{~h}$ (Figure 1a, lanes 4, 8, 12), suggesting that this is a very stable protein. In contrast, p21 levels decreased dramatically $3 \mathrm{~h}$ post-treatment (lanes $2,6,10$ ) confirming the efficiency of the $\mathrm{CHX}$ treatment. SSRP1 stability was confirmed using other translation inhibitors (puromycin, emetin) and by pulse-chase experiments (data not shown). However, SSRP1 displayed a much shorter halflife ( $<9 \mathrm{~h}$, Figure 1b) in Tera-2 (teratocarcinoma) cells. Since even mild physiological stresses trigger apoptosis in these cells, ${ }^{24}$ we suspected that $\mathrm{CHX}$ treatment might have induced the same effect. The increase in the $89 \mathrm{kDa}$ apoptotic PARP fragment at 9 and $24 \mathrm{~h}$ (lanes 3 and 4) confirmed this hypothesis and suggested that SSRP1 is degraded during apoptosis. To investigate more precisely this possibility, we developed two monoclonal antibodies against SSRP1, detecting specifically the N-terminal (clone 1G6) and the C-terminal part of the protein (clone 4F7). Figure 1c displays the approximate position of the corresponding epitopes in human SSRP1, which is aligned with its yeast counterparts Pob3 and Nhp6 (Figure 1c and Supplementary Figure 1).

\section{SSRP1 is cleaved into two fragments during apoptosis}

The fate of SSRP1 was monitored in UVC-irradiated $\left(20 \mathrm{~J} / \mathrm{m}^{2}\right)$ Tera- 2 cells during a $25 \mathrm{~h}$ time course (Figure $2 \mathrm{a}$ ). With the progressive decrease in full-length SSRP1, two smaller fragments were generated: a $52 \mathrm{kDa}$ product was detected by $1 \mathrm{G} 6$, thus belonging to the $\mathrm{N}$-terminal part of the protein, whereas 4F7 specifically detected a C-terminal, $35 \mathrm{kDa}$ product. Their combined molecular weight was approximately equal to the full-length protein $(87 \mathrm{kDa})$, suggesting that SSRP1 is subjected to a single cleavage. Detection of PARP and DNA-PKcs, two known apoptotic targets, ${ }^{25}$ showed a similar decrease of the full-length with appearance of shorter forms. In contrast, Spt16 levels did not decrease (data not shown). These results indicate that SSRP1 is cleaved into two fragments during UVC-induced apoptosis in Tera-2 cells.

To test whether SSRP1 cleavage is a general characteristic of apoptosis, several human cell lines (Tera-2, U2OS and human epithelial kidney HEK293) were treated with different chemicals (kinase inhibitor DRB, proteasome inhibitor MG132, calpain and proteasome inhibitor ALLN) and highdose UVC $\left(100 \mathrm{~J} / \mathrm{m}^{2}\right)$, all stimuli inducing apoptosis through the intrinsic pathway. Stimulation of the extrinsic pathway was performed using tumor necrosis factor- $\alpha$ (TNF- $\alpha)$ in combination with $\mathrm{CHX}(\mathrm{CHX})$ (Figure $2 \mathrm{~b})$.

SSRP1 apoptotic cleavage was observed in all the cell lines tested with variations depending on the treatment. For instance, DRB and UVC strongly induced apoptosis in Tera-2 cells, but were less effective in HEK293 or U2OS (Figure 2b, lanes 2-3, 9-10, 16-17) as monitored by C-PARP. Proteasome inhibitors have emerged recently as potent apoptosis inducers even in resistant cell lines. ${ }^{26}$ Accordingly, MG132 and ALLN were the only stimuli able to induce apoptosis in the three cell lines (Figure 2b, lanes 4-5, 11-12, 18-19). Finally, TNF- $\alpha$ treatment was efficient in Tera-2 and U2OS cells (lanes 7 and 21) but not in HEK293 (lane 14) cells.

In summary, SSRP1 cleavage appears to be a general occurrence during apoptosis, like PARP and DNA-PKcs. 
a

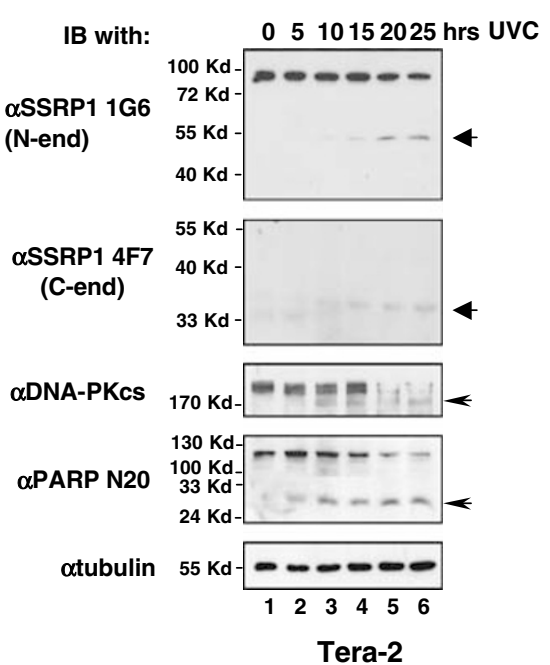

b

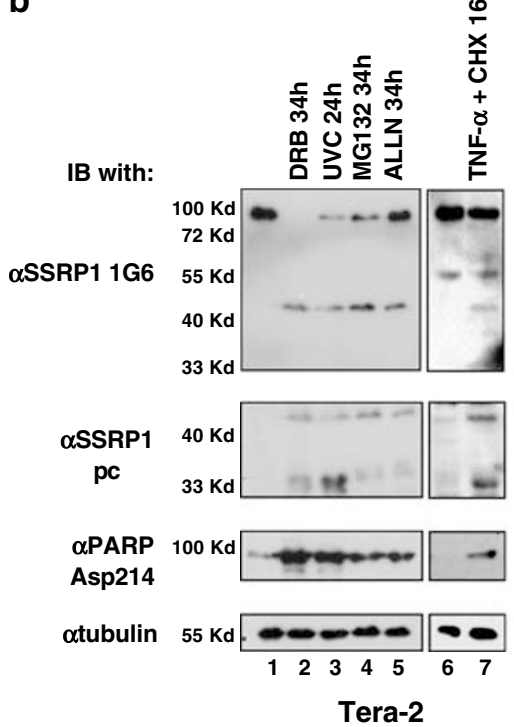

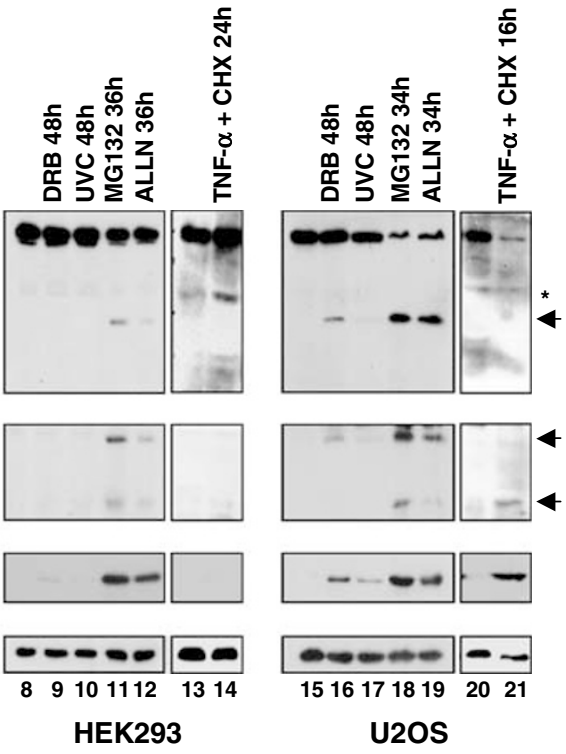

Figure 2 SSRP1 is cleaved into two fragments during apoptosis. (a) Cleavage of endogenous SSRP1 during UVC-induced apoptosis. Tera-2 cells irradiated with UVC $\left(20 \mathrm{~J} / \mathrm{m}^{2}\right)$ were harvested at the indicated times and $30 \mu \mathrm{g}$ proteins analyzed by immunoblot using SSRP1 monoclonal $1 \mathrm{G} 6$ and $4 \mathrm{~F} 7$ antibodies. SSRP1 full-length and apoptotic fragments are marked by bold arrows, as in the next figures. Apoptosis was monitored using DNA-PKcs and PARP cleavage fragments (170 and $29 \mathrm{kDa}$, respectively; sharp arrows, as in next figures). (b) Apoptotic cleavage of SSRP1 occurs in different cell lines treated with different apoptotic inducers. Tera-2, HEK293 and U2OS cells were treated as indicated. SSRP1 and apoptotic fragments were detected as in Figure 1b using $1 \mathrm{G} 6$ and the polyclonal antibody (detecting both apoptotic fragments)

$\mathbf{a}$

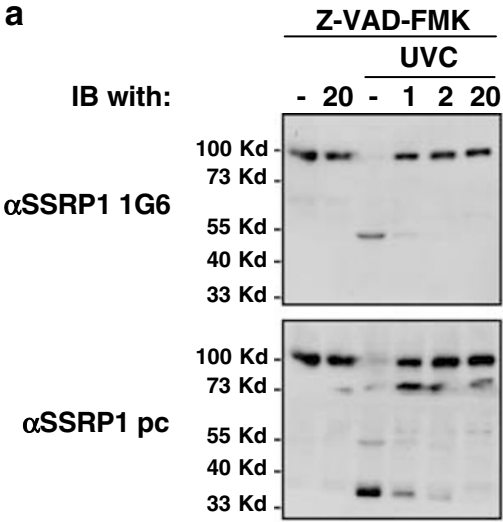

$\alpha$ PARP N20

atubulin

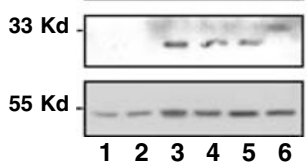

Z-DEVD-FMK UVC
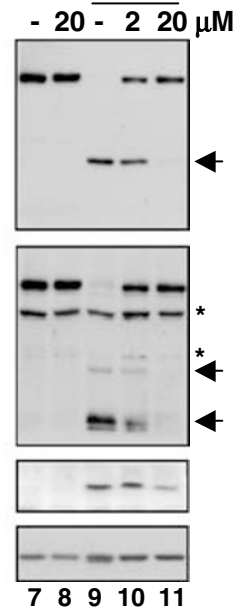

b

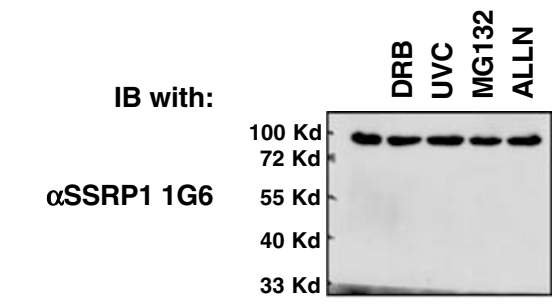

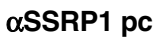

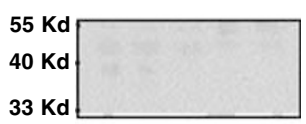

$\alpha$ PARP Asp 214

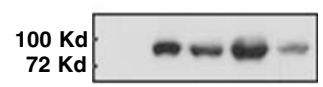

otubulin

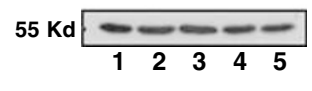

MCF7

Tera-2 cells

Figure 3 Apoptotic cleavage of SSRP1 is prevented in cells where caspases 3 and 7 are inhibited or deficient. (a) Caspase inhibitors block the apoptotic cleavage of SSRP1. Tera-2 cells were treated with Z-VAD-FMK or Z-DEVD-FMK (pan-capase and caspase $3 / 7$ inhibitors) prior to UVC irradiation ( $\left.40 \mathrm{~J} / \mathrm{m}^{2}\right)$. After $24 \mathrm{~h}, \mathrm{cells}$ were harvested and $30 \mu \mathrm{g}$ of total proteins were analyzed by immunoblot. The $29 \mathrm{kDa}$ apoptotic fragment of PARP was probed to assess the apoptotic induction and the effect of the capase inhibitors. (b) SSRP1 is not cleaved in apoptotic MCF7 cells. Caspase 3/7-deficient MCF7 cells were treated with various apoptosis inducers as indicated and cell lysates were analyzed as in Figure $1 b$

\section{Endogenous SSRP1 is cleaved by caspase 3 and/or 7}

During apoptosis, effector caspases such as caspases 3 and 7 are responsible for the cleavage of a broad panel of proteins. $^{27}$ To test whether SSRP1 is a caspase target during apoptosis, we tested the ability of caspase inhibitors to prevent its cleavage. After incubation with different concentrations of the pan-caspase inhibitor Z-VAD-FMK and the caspase 3/7 inhibitor Z-DEVD-FMK for $30 \mathrm{~min}$, Tera-2 cells were UVC-irradiated and SSRP1 levels were analyzed at $24 \mathrm{~h}$ by immunoblot (Figure 3a). Z-VAD and Z-DEVD treatment 
alone did not affect SSRP1 (compare lanes 1 and 2, 7 and 8), whereas UVC induced the complete disappearance of the full-length protein with generation of two cleavage fragments (Figure 3a, lanes 3, 9). Treatment with $1 \mu \mathrm{M}$ Z-VAD efficiently blocked SSRP1 cleavage (lanes 4-6). Interestingly, PARP cleavage was less sensitive to caspase inhibitors, as $2 \mu \mathrm{M}$ Z-VAD did not affect the production of the $29 \mathrm{kDa}$ product (Figure 3a, lanes 3-5). Z-DEVD treatment was less efficient than Z-VAD (Figure 3a, compare lanes 5-6 and 10-11). This result is not surprising since $Z-V A D$, by inhibiting a wide range of caspases, is expected to block apoptosis more efficiently than Z-DEVD that targets primarily caspases 3 and 7 .

To confirm the specific cleavage of SSRP1 by caspase 3 and/or 7, we employed the MCF7 cell line (Figure 3b) that is caspase 3-deficient and caspase 7-inactive (Supplementary Figure 2a). ${ }^{25}$ Apoptosis was efficiently induced by DRB, UVC, MG132 and ALLN (Figure 3b, lanes 2-5) as demonstrated by the cleavage of PARP. ${ }^{25}$ However, SSRP1 was not reduced compared to untreated cells and no apoptotic fragments were detected (Figure 3b, lanes 2-5). Taken together, these results suggest that SSRP1 is specifically cleaved by caspase 3 and/ or 7 in vivo.

\section{SSRP1 is cleaved in vitro by caspases 3 and 7 at the conserved $\mathrm{DQHD}_{450}$ site}

Caspases cleave their substrates after a tetrapeptide recognition site with an aspartic acid (D) required in position $\mathrm{P} 1$. For caspases 3 and 7 , the consensus sequence is $D E V D_{\mathrm{P} 1}$, but a wide variation in the two central residues has been observed. $^{28}$ Several DXXD motifs are present in SSRP1, but only one, $\mathrm{DQHD}_{450}$, generated predicted fragments with sizes ( 51 and $29 \mathrm{kDa}$ ) corresponding to the in vivo products (52 and $35 \mathrm{kDa})$. This site, located in the acidic domain of SSRP1, is evolutionarily conserved (Figure 4a). To test whether $\mathrm{DQHD}_{450}$ is the caspase cleavage site in human SSRP1, $D_{450}$ was mutated to alanine $(A)$ in SSRP1 expression vectors. Purified wild-type (wt) SSRP1 or SSRP1 D450A was incubated with recombinant active caspase 3 or 7 for $4 \mathrm{~h}$ at $37^{\circ} \mathrm{C}$. As shown in Figure $4 \mathrm{~b}$, both caspases cleaved wt SSRP1 (lanes 2-5), but not SSRP1 D450A (lanes 7-10). Of note, a $60 \mathrm{kDa}$ product was sometimes detected and might be an SSRP1 fragment generated from an alternative cleavage site (Figure 4b, lanes 2, 3, 5, 8). MDM2, a known caspase 3 target, was used as a positive control (Supplementary a

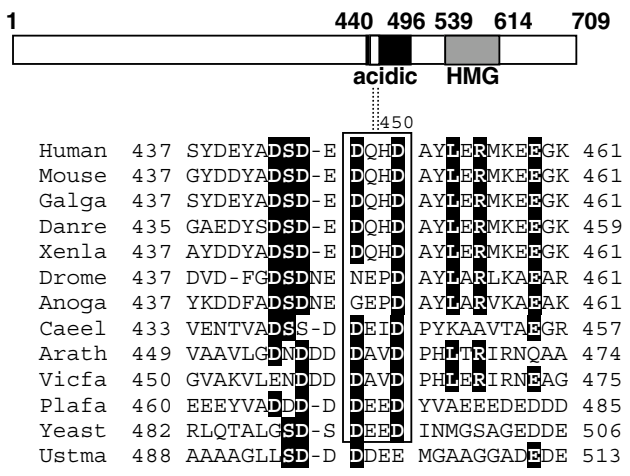

b

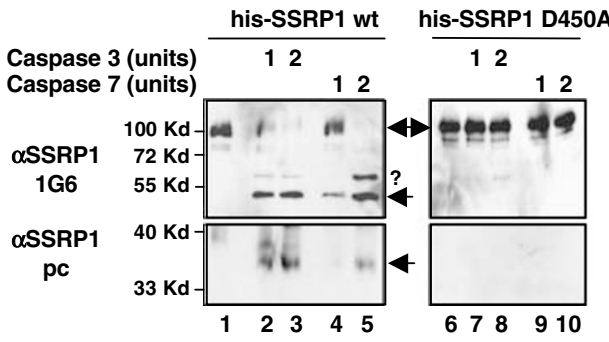

C

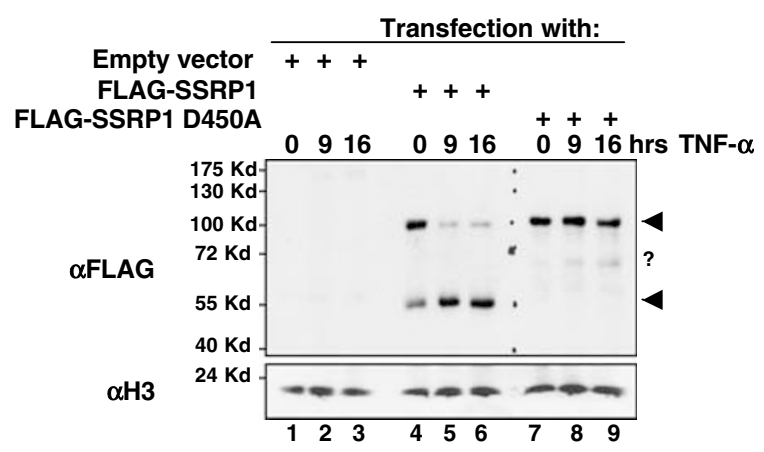

d

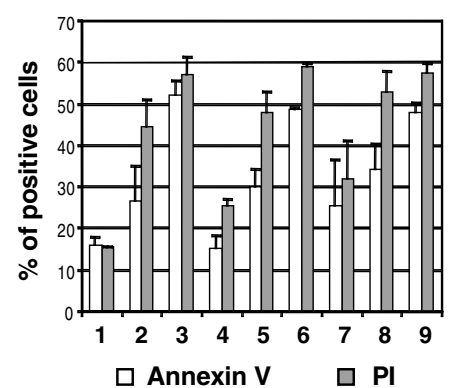

Figure 4 SSRP1 is cleaved at the $\mathrm{DQHD}_{450}$ site. (a) Alignment of the SSRP1 caspase-cleavage site from various organisms. SSRP1 sequences from fungi (i.e. Pob3) to mammals were aligned and the region surrounding the caspase-cleavage site (boxed in the alignment) is shown with highly conserved residues highlighted in black. First and last residue of each sequence is numbered, as well as the conserved D450 in the human protein. Position of the putative caspase site is indicated on the SSRP1 schematic along with the acidic and HMG domains. Galga, Gallus gallus (bird); Danre, Danio rerio (fish); Xenla, Xenopus laevis (frog); Drome, Drosophila melanogaster, Anoga, Anopheles gambiae (insects), Caeel, Caenorhabditis elegans (round worm); Arath, Arabidopsis thaliana; Vicfa, Vicia faba (plants); Plafa, Plasmodium falciparum (protist); Ustma, Ustilago major (fungus). (b) SSRP1 but not SSRP1 D450A is cleaved in vitro by caspases 3 and 7. Purified his-SSRP1, hisSSRP1 D450A and FLAG-Spt16 were incubated with different activities of caspase 3 or 7 and analyzed by immunoblot. The question mark indicates a possible alternative cleavage product. (c) SSRP1 but not SSRP1 D450A is cleaved in apoptotic cells. U2OS cells were transfected with FLAG-SSRP1 or FLAG-SSRP1 D450A for $24 \mathrm{~h}$ before treatment with TNF- $\alpha+\mathrm{CHX}$ for the indicated times. In all, $15 \mu \mathrm{g}$ of total proteins was analyzed by immunoblot using the FLAG antibody to detect SSRP1 and its $\mathrm{N}$-terminal cleavage fragment. Equal loading was assessed using histone H3. (d) FACS analysis. Nonfixed cells corresponding to each of the samples described in panel (c) were stained with annexin V-FITC/propidium iodide (PI) and analyzed by FACS. Histograms represent the average percentage of annexin V-and PI-positive cells from two independent experiments. Error bars are indicated 
Figure $2 b)$. In contrast, these caspases did not cleave Spt16 (Figure 4b, lanes 12-15).

To confirm this result in vivo, U2OS cells transfected with FLAG-SSRP1 and FLAG-SSRP1 D450A were treated with $\mathrm{TNF}-\alpha+\mathrm{CHX}$ to induce apoptosis. Cells were analyzed by immunoblot (Figure 4c) and fluorescence-activated cell sorting (FACS) to monitor the population of apoptotic cells using annexin V-FITC/propidium iodide (PI) (Figure 4d). Cleavage of wt SSRP1 was concomitant with the increase of the FLAGtagged $\mathrm{N}$-terminal fragment following apoptosis induction (Figure $4 \mathrm{c}$ and $\mathrm{d}$, lanes 5 and 6). Low levels of the $\mathrm{N}$-terminal fragment were detected in untreated cells (Figure 4c, lane 4), probably because the transfection reagent can induce apoptosis by itself (Figure 4d, lanes 1, 4, 7). In contrast, mutated SSRP1 was resistant to cleavage (Figure 4c, lanes 8 and 9), but detection of a faint $60 \mathrm{kDa}$ product (lanes 8 and 9) also seen in vitro (Figure $4 \mathrm{~b}$ ) may indicate a weak alternative cleavage site. No significant difference was observed in the percentage of annexin V/PI-positive cells between wt and mutant SSRP1 (Figure 4d, lanes 4-9), suggesting that SSRP1 cleavage did not alter the progression of apoptosis. These results demonstrate that SSRP1 is cleaved during apoptosis at the $\mathrm{DQHD}_{450}$ site.

\section{Apoptotic cleavage affects the association of SSRP1 with chromatin}

In nonapoptotic cells, SSRP1 is a chromatin-associated protein with the other FACT subunit, Spt16. ${ }^{7,10}$ To monitor the fate of the SSRP1 fragments after apoptotic cleavage, Tera-2 cells treated or not with UVC were lysed in radioimmunoprecipitation assay (RIPA) buffer and the chromatin fraction separated from soluble proteins as described in Material and Methods. Separation was confirmed by immunoblot using histone $\mathrm{H} 3$ and Spt16 as chromatin markers and PARP as a nonchromatin marker (Figure 5a, compare lanes 3-4 and 5-6). In untreated cells, full-length SSRP1 was found in both fractions (lanes 3 and 5), probably partially stripped from chromatin due to the high stringency of the lysis conditions ( $1 \%$ sodium deoxycholate, $1 \%$ NP-40, $0.1 \%$ SDS). In apoptotic cells, immunoblots revealed a striking separation between the $\mathrm{C}$ - and $\mathrm{N}$-terminal cleavage fragments, found essentially in the soluble and chromatin fractions, respectively (Figure $5 \mathrm{a}$, lanes 4 and 6 ). This result suggests that, upon SSRP1 cleavage, the C-terminal product does not tightly associate with chromatin and is released in the

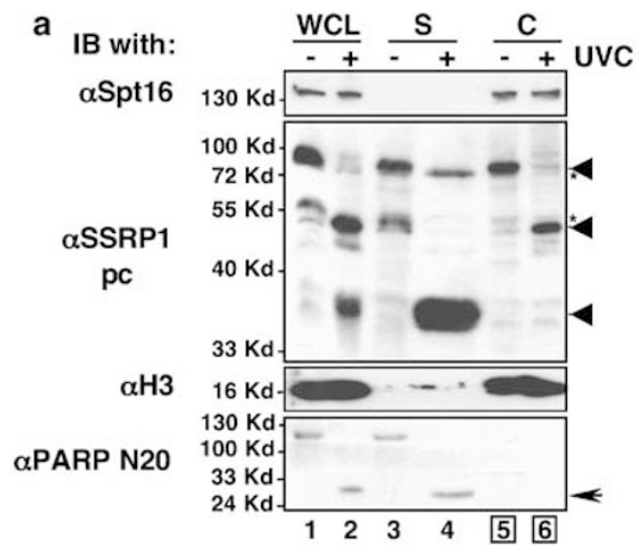

b IB with:

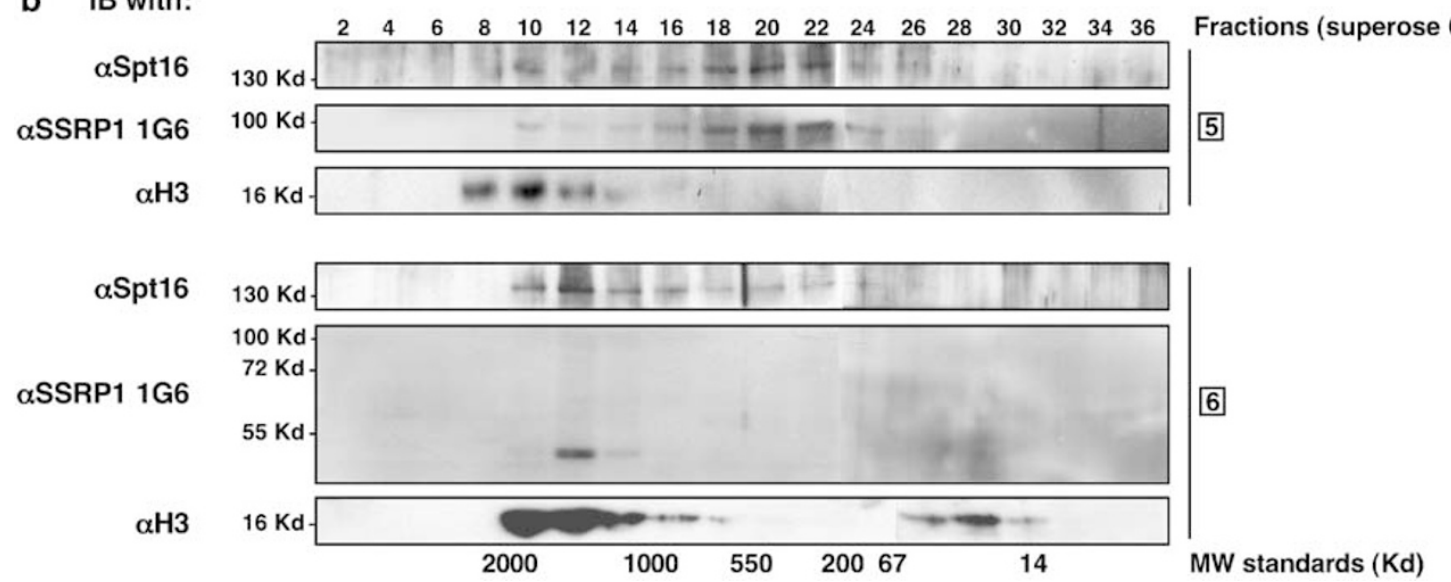

Figure 5 Apoptotic cleavage of SSRP1 alters its association with chromatin in vivo. (a) The N-and C-terminal SSRP1 apoptotic fragments are found in different cellular fractions. Whole-cell lysates (WCL) from Tera-2 cells treated or not with UVC were separated between soluble (S) and resolubilized chromatin (C) fractions and analyzed by immunoblot. SSRP1 polyclonal antibody detected full-length and both apoptotic fragments. Spt16, histone H3 and PARP were used as chromatin and nonchromatin markers, respectively. Quantity of total proteins loaded: WCL and C, $20 \mu \mathrm{g} ; \mathrm{S}, 50 \mu \mathrm{g}$. (b) The SSRP1 N-terminal product co-elutes with Spt16 and histone H3. A total of 100 and $230 \mu \mathrm{g}$ of chromatin fractions from untreated and UVC-treated cells, respectively (boxed numbers below panel (a) were further fractionated through a gel filtration (superose 6) column. Resulting fractions (numbered above the figure) were analyzed by immunoblot. MW standards are positioned below the figure 
soluble fraction. This was confirmed using a low stringency lysis buffer $(200 \mathrm{~mm} \mathrm{NaCl}, 0.25 \%$ Triton X-100) instead of RIPA buffer. Under these conditions, the C-terminal product was also essentially found in the soluble fraction (data not shown). To investigate whether the $\mathrm{N}$-terminal fragment remained bound to chromatin in association with Spt16, chromatin fractions from untreated and apoptotic cells (corresponding to Figure $5 \mathrm{a}$, lanes 5 and 6 ) were separated on a gel filtration column and the resulting fractions analyzed by immunoblot (Figure 5b). In the untreated sample (top panel), SSRP1 and Spt16 strictly co-eluted in two peaks. The first one (fraction 10) was discrete and probably corresponds to the chromatin-associated FACT as it co-eluted with histone $\mathrm{H} 3$ as a high molecular weight complex. The second peak (fractions 18-24) was more abundant, eluted with an apparent MW of 200-500 kDa and was not associated with histone H3. It likely corresponds to the free form of FACT released from chromatin during the sonication step of the chromatin fractionation procedure (see Materials and Methods). In the UVC-treated sample, the N-terminal SSRP1 fragment co-eluted with Spt16 as a single, high MW peak (fraction 12, about $1500 \mathrm{kDa}$ ). Histone $\mathrm{H} 3$ was found in the same fraction, suggesting that this peak corresponds to the chromatinassociated, truncated form of FACT. Histone $\mathrm{H} 3$ also eluted as a free form (fractions 26-30), probably released from apoptotic chromatin. In contrast with the untreated sample, no or low levels of the free forms of SSRP1 $\mathrm{N}$-terminal fragment and Spt16 were detected, despites the harsh extraction conditions (RIPA buffer and sonication). This suggests that the truncated form of FACT is more tightly associated with chromatin than the intact FACT.

In summary, our results suggest that, during apoptosis, the C-terminal part of SSRP1 is released from chromatin while the $\mathrm{N}$-terminal fragment remains bound to Spt16 in tight association with chromatin.

\section{The SSRP1 apoptotic N-terminal fragment is stabilized by MG132}

Interestingly, in U2OS where SSRP1 levels dramatically decreased following TNF- $\alpha$ treatment, the N-terminal apoptotic fragment was not detected by SSRP1 antibodies (Figure $2 b$, lane 21). In contrast, this product was detected in cells treated with proteasome inhibitors (Figure $2 b$, compare lane 21 with 18-19). The C-terminal part did not show the same discrepancy, displaying similar levels in MG132-, ALLN- and TNF- $\alpha$-treated cells. These observations suggested that the SSRP1 N-terminal cleavage fragment undergoes proteasome-mediated degradation during apoptosis induced by TNF- $\alpha$ in U2OS cells. To test this hypothesis, U2OS cells transfected with FLAG-SSRP1 were treated with UVC or MG132, and SSRP1 cleavage monitored by immunoblot using the FLAG antibody (Figure 6a). Cleavage of DNAPKcs showed the equivalent apoptosis induction following both treatments, a result confirmed by the similar level of remaining full-length SSRP1 (Figure 6a, compare lanes 2 and 3). However, the N-terminal fragment accumulated at least three-fold more in MG132- than in UVC-treated cells, suggesting that MG132 prevented the proteasomal degradation of this apoptotic product. Instability of this fragment was further confirmed by its marginal increase in UVCtreated compared to untreated cells despite the dramatic decrease of full-length SSRP1 (Figure 6a, lanes 1 and 2).

To test whether MG132 could stabilize the endogenous fragment, we monitored the SSRP1 level in U2OS cells treated either with MG132 or TNF- $\alpha+\mathrm{CHX}$ during a $24 \mathrm{~h}$ time course (Figure 6b). Bands corresponding to the full-length protein (I), the $\mathrm{N}$-terminal (II) and the $\mathrm{C}$-terminal (III) cleavage fragments were quantified and plotted as a function of time (Figure 6c). First, the kinetics of DNA-PKcs cleavage showed a significant delay in cells treated with MG132 compared to TNF- $\alpha$ (top panel of Figure 6b, lanes 2 and 7). Full-length SSRP1 curves (Figure 6c, upper graph) confirmed this trend by displaying a similar rate of decrease but with a $5 \mathrm{~h}$ delay in the case of MG132. Upon TNF- $\alpha$ treatment, the N-terminal apoptotic fragment showed a parabolic curve (Figure 6c, middle graph, dashed line), with accumulation during the first phase of SSRP1 cleavage (0-10 h) followed by a degradation phase $(10-24 \mathrm{~h})$. The parabolic shape suggests that this fragment is subjected to a dynamic equilibrium between production (due to the cleavage of the full length) and degradation. Upon MG132 treatment, this $52 \mathrm{kDa}$ product reached higher levels and decreased slower (Figure 6c, middle graph, solid line), suggesting that it is subjected to proteasomal degradation. By contrast, the C-terminal product displayed a different dynamic with continuous accumulation during TNF- $\alpha$-induced apoptosis (Figure 6b, lanes 7-9 and Figure 6c, lower graph, dashed line), suggesting that this product is more stable and not subjected to proteasomal degradation. Confirming this observation, MG132 was unable to stabilize this fragment (Figure $6 \mathrm{~b}$, lanes 3 and 4 and Figure 6c, lower graph, solid line). These results suggest that the SSRP1 N-terminal, but not C-terminal, apoptotic fragment is subjected to proteasomal degradation.

\section{SSRP1 and its apoptotic N-terminal fragment are ubiquitylated in cells}

To study the ubiquitylation of a protein that is also an apoptotic target, it is necessary to find experimental conditions under which proteasome inhibitors block the ubiquitin-proteasome pathway without inducing apoptosis. The H1299 cell line is interesting in this regard because it is resistant to apoptosis (Supplementary Figure 3). ${ }^{26}$ First, H1299 cells were transfected with FLAG-SSRP1 and his-ubiquitin or his-ubiquitin K48R (a mutant unable to form poly-ubiquitin chains) before MG132 treatment. Immunoblots demonstrated the equal expression of FLAG-SSRP1 and the presence of the $\mathrm{N}$-terminal SSRP1 fragment (Figure 7a, bottom panel, lanes 4-6). Ubiquitylation assay was performed using the rest of the whole-cell lysate (WCL) with detection of ubiquitylated SSRP1 using the FLAG antibody (Figure 7a, top panel). Although fulllength SSRP1 and its $\mathrm{N}$-terminal fragment bound to the Ni-NTA beads nonspecifically (Figure 7a, lane 4), both were ubiquitylated in the presence of ubiquitin (lane 5). The use of mutated ubiquitin almost abolished the ladder with detection of a single higher band, probably corresponding to the mono-ubiquitylated form (lane 6). This suggests that both the 
a

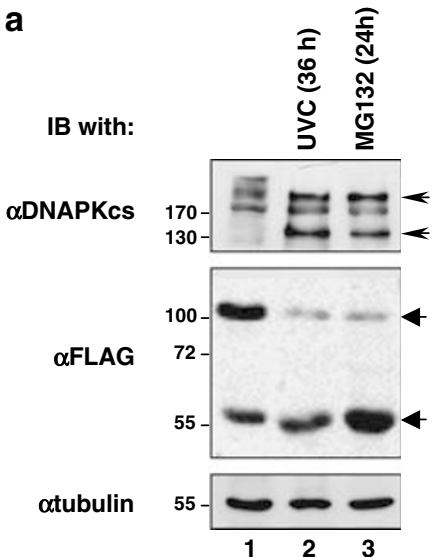

b

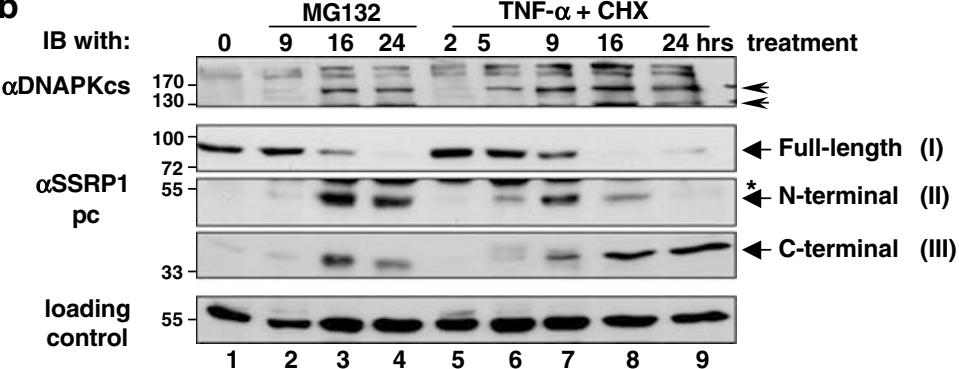

C

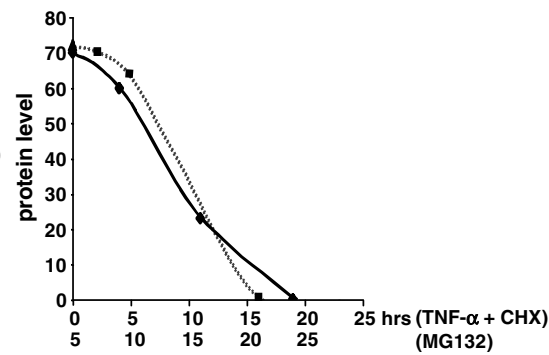

(II)

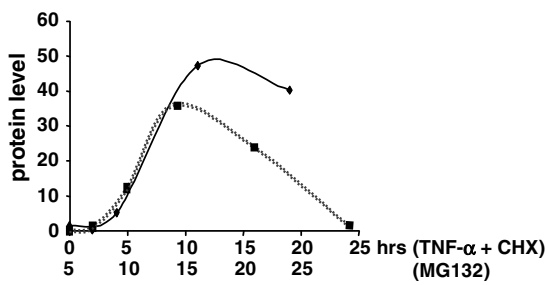

(III)

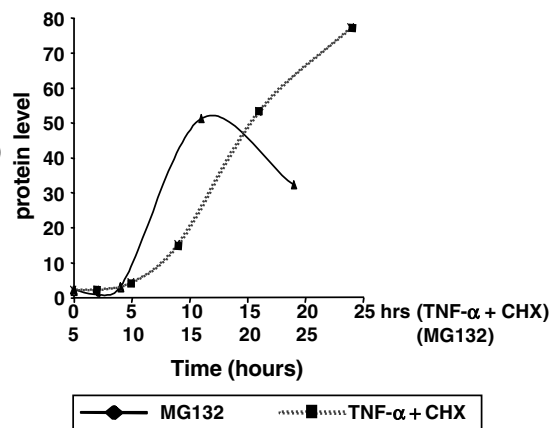

Figure 6 The SSRP1 apoptotic N-terminal fragment is stabilized by MG132. (a) The SSRP1 N-terminal fragment accumulates during MG132- compared to UVCinduced apoptosis in a transient expression system. U2OS cells were transfected with FLAG SSRP1 for $24 \mathrm{~h}$ before treatment either with UVC $\left(100 \mathrm{~J} / \mathrm{m}^{2}\right)$ or MG132 $(10 \mu \mathrm{M})$ for the indicated times. In total, $20 \mu \mathrm{g}$ of total proteins were analyzed by immunoblot. (b) SSRP1 dynamics during MG132- and TNF- $\alpha$ induced apoptosis. U2OS cells were treated with either MG132 or TNF- $\alpha+\mathrm{CHX}$ and harvested at the indicated times. In total, $30 \mu \mathrm{g}$ of total proteins were analyzed by immunoblot. The SSRP1 full-length (I), and its $\mathrm{N}$ - and C-terminal apoptotic fragments (II and III) were detected using the SSRP1 polyclonal antibody. This result was reproduced using monoclonal anti-SSRP1 antibodies (data not shown). Loading control corresponds to a nonspecific band detected by the same antibody. Asterisk denotes nonspecific bands. (c) The SSRP1 N-terminal but not the C-terminal cleavage fragment is stabilized by MG132. For each time point shown in panel (b), the bands corresponding to the full-length SSRP1 protein (I, upper graph), and its N- (II, middle graph) and C-terminal (III, lower graph) apoptotic fragments, respectively, were quantified and plotted as a function of time. As apoptosis induced by MG132 (solid lines) is delayed by $5 \mathrm{~h}$ compared to TNF- $\alpha+\mathrm{CHX}$ (dashed lines), the time course begins at $5 \mathrm{~h}$ for MG132-treated samples in each graph. Protein levels are in arbitrary units

full-length and N-terminal apoptotic fragments of SSRP1 are ubiquitylated in cells.

To confirm this result, a similar assay was performed using cells transfected with SSRP1 or SSRP1 D450A and harvested at different time points after MG132 treatment. (Figure 7b). Here, MG132 was used as both proteasome inhibitor and apoptosis induction agent. Immunoblots (bottom panels) showed the time-dependent increase of the apoptotic $\mathrm{N}$-terminal fragment in wild-type but not in mutant SSRP1transfected cells (Figure 7b, compare lanes 1-4 and 5-8). Cleavage of DNA-PKcs confirmed the apoptosis induction. Ni-NTA pull-down coupled with FLAG detection (top panel) showed the nonspecific binding of SSRP1 full-length $(100 \mathrm{kDa})$ and $\mathrm{N}$-terminal fragment $(55 \mathrm{kDa})$ to the beads. However, two higher products of 110 and $65 \mathrm{kDa}$ were detected for SSRP1 (Figure 7b, lanes 1-4), whereas only the $110 \mathrm{kDa}$ species was detected for SSRP1 D450A (lanes $5-8)$. These higher products likely correspond to monoubiquitylated forms of SSRP1 as the molecular weight of one his-ubiquitin is about $10 \mathrm{kDa}$. For the wild-type SSRP1, intensity of the poly-ubiquitin chain increased more dramatically at $48 \mathrm{~h}$ (Figure $7 \mathrm{~b}$, lane 4 ). In contrast, this increase was not seen for the SSRP1 D450A mutant (lane 8), suggesting that most SSRP1 ubiquitylation during apoptosis occurs on the $\mathrm{N}$-terminal cleavage product (Figure 6).

\section{Ubiquitylation and proteasome inhibitor- dependent stabilization of exogenous SSRP1 fragments are consistent with the fate of the endogenous protein}

To study the correlation between SSRP1 ubiquitylation and proteasomal degradation, a series of experiments using SSRP1 fragments transiently expressed in $\mathrm{H} 1299$ cells were conducted. First, FLAG-tagged SSRP1 fragments (1-242, 235-475 and 472-709) were used for in vivo ubiquitylation assays in the absence or presence of MG132 (Figure 8a). Immunoblots (bottom panels) revealed that both the 1-242 and 235-475 fragments (Figure 8a, lanes 1-4) but not the 

Transfection with:

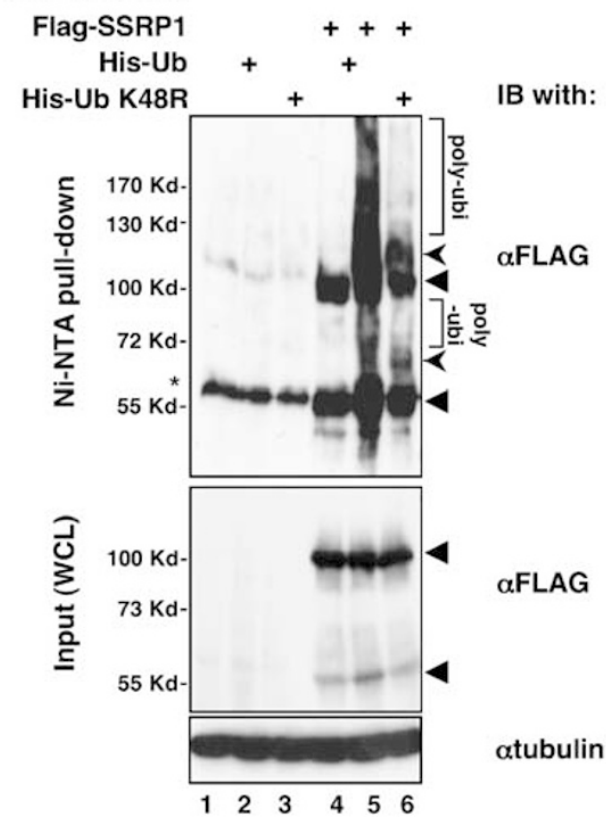

b

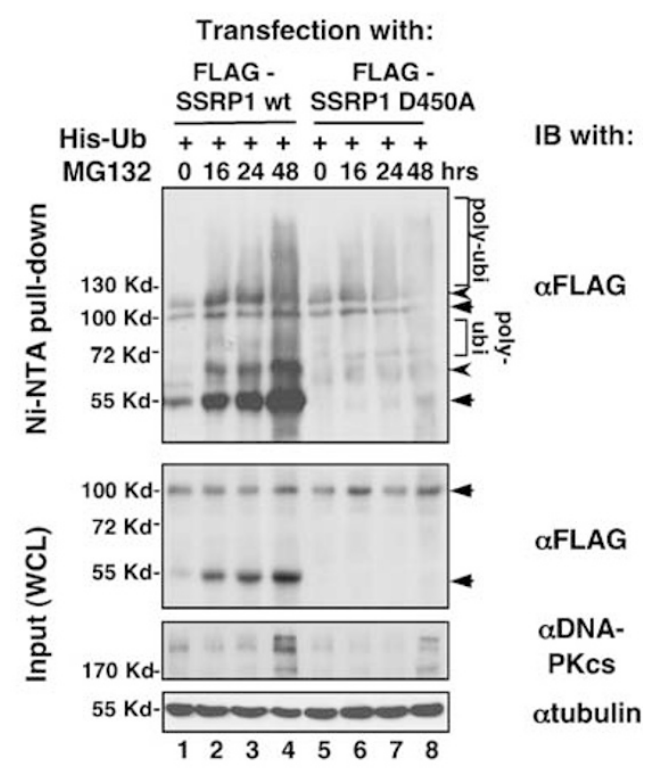

Figure 7 SSRP1 and its N-terminal apoptotic fragment are ubiquitylated in vivo. (a) Poly-ubiquitylation of SSRP1 is abolished by the use of ubiquitin K48R. H1299 cells were transfected as indicated and treated with MG132 for $16 \mathrm{~h}$. After harvest, 10 and $400 \mu \mathrm{g}$ of total proteins were used in immunoblots (bottom panels) and for Ni-NTA pull-down of ubiquitylated proteins (top panel), respectively. SSRP1 and its N-terminal cleavage product were detected using FLAG antibody. Triangles and arrowheads indicate SSRP1 non- and mono-ubiquitylated forms, respectively. Poly-ubi, poly-ubiquitin ladder. (b) Time course of SSRP1 ubiquitylation during MG132 treatment. H1299 cells were transfected for $24 \mathrm{~h}$ as indicated, treated with MG132 and harvested at various times post-treatment. Samples were then processed as in (a)

472-709 fragment (lanes 5-6) are stabilized by MG132, in agreement with the endogenous data (Figure 6). The Ni-NTA pull-down (top panel) strengthened the link between proteasomal degradation and ubiquitylation, as both the 1-242 fragment and to a lesser extent the 235-475 fragment (Figure 8a, lanes 1-4), but not the 472-709 fragment (lanes 5 and 6), were ubiquitylated in vivo, with MG132dependent enhancement of the poly-ubiquitin ladder of the 1-242 fragment (lanes 1 and 2) and oligo-ubiquitylated forms of the 235-472 fragment (lanes 3 and 4). However, it is currently unclear why the higher ubiquitin ladder of the 235-475 fragment (above $55 \mathrm{kDa}$ ) was not enhanced by MG132 (Figure 8a, lanes 3 and 4). To map more precisely the ubiquitylation in the $\mathrm{N}$-terminus, similar experiments were performed using three shorter fragments. As shown in Figure 8b, the 1-242 and 125-235 fragments (lanes 4 and 6) but not the 1-160 fragment (lane 2) display a poly-ubiquitin ladder, suggesting that ubiquitylated sites are between aa 160 and 235. Accordingly, MG132 and ALLN only stabilized fragments encompassing the 160-235 region (Figure $8 \mathrm{c}$ ). In summary, exogenous results collectively support endogenous data, suggesting that the apoptotic N-terminal fragment of SSRP1 is degraded through the ubiquitin-proteasome pathway.

\section{Discussion}

In this study, we describe the dual pathway of SSRP1 degradation during apoptosis. SSRP1 is first cleaved by caspase 3 and/or 7 into a $52 \mathrm{kDa} \mathrm{N}$-terminal and a $35 \mathrm{kDa}$
C-terminal fragment. As summarized in Figure 8d, exogenous and endogenous $\mathrm{N}$-terminal SSRP1 fragments are similarly processed, with a good correlation between ubiquitylation and proteasomal degradation. These data demonstrate that the $52 \mathrm{kDa}$ apoptotic product is subsequently targeted to proteasomal degradation by ubiquitylation.

\section{SSRP1 is cleaved into two fragments upon apoptosis induction}

SSRP1 stability is altered when cells undergo apoptosis (Figure 1b). Time course experiments using different cell lines showed that SSRP1 cleavage occurs simultaneously with two early apoptotic markers, DNA-PKcs and PARP, ${ }^{29,30}$ suggesting that SSRP1 cleavage is an early apoptotic event. The $\mathrm{N}$-terminal apoptotic fragment was not detectable in U2OS cells because of its degradation through the ubiquitin-proteasome pathway. By contrast, apoptotic Tera-2 cells retained high levels of this $52-\mathrm{kDa}$ product with no stabilization by proteasome inhibitors (Figures 2 and 5), suggesting that this fragment is not targeted for proteasomal degradation. It is likely that the E3 ligase responsible for the poly-ubiquitylation of the $\mathrm{N}$-terminal apoptotic fragment is not active or absent in this cell line.

\section{SSRP1 is cleaved by caspase 3 and/or 7 at the novel $\mathrm{DQHD}_{450}$ site}

Several lines of evidence support SSRP1 cleavage by caspase 3 and/or 7 . First, the caspase 3/7 inhibitor Z-DEVD 
a Transfection with:

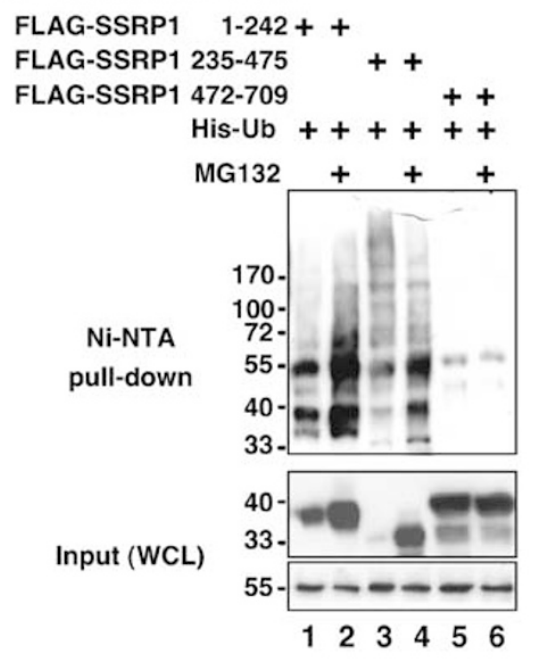

b Transfection with:

FLAG-SSRP1 1-160 + +

FLAG-SSRP1 1-242

FLAG-SSRP1 125-235

IB with:

$\alpha$ FLAG

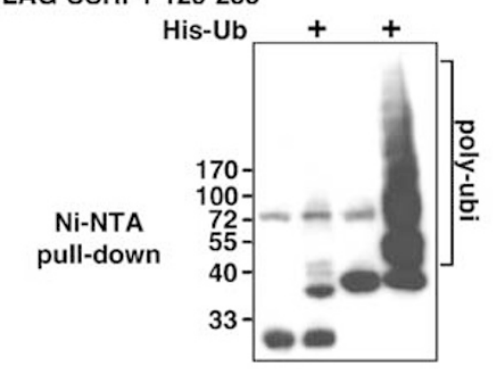

$\alpha$ FLAG

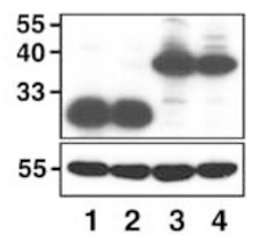

atubulin

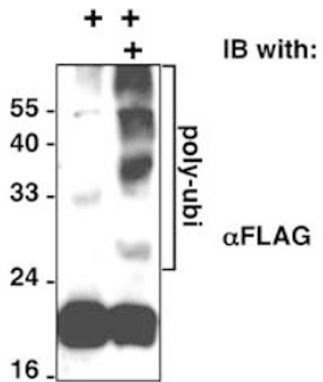

16.

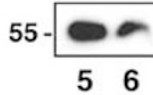

$\alpha$ FLAG

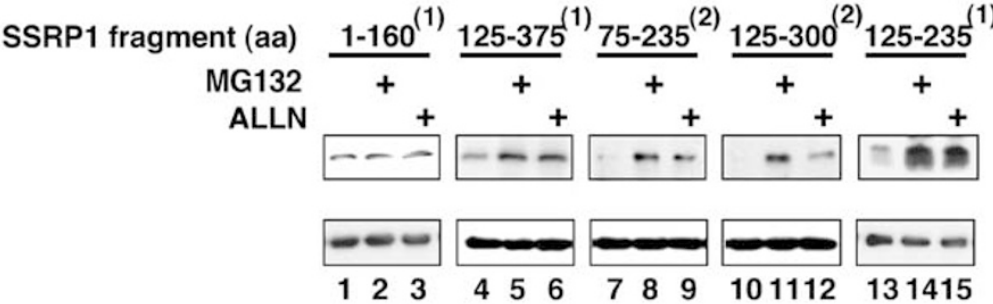

IB with:

(1) $\alpha$ FLAG or

(2) $\alpha$ SSRP1 pc

atubulin

d

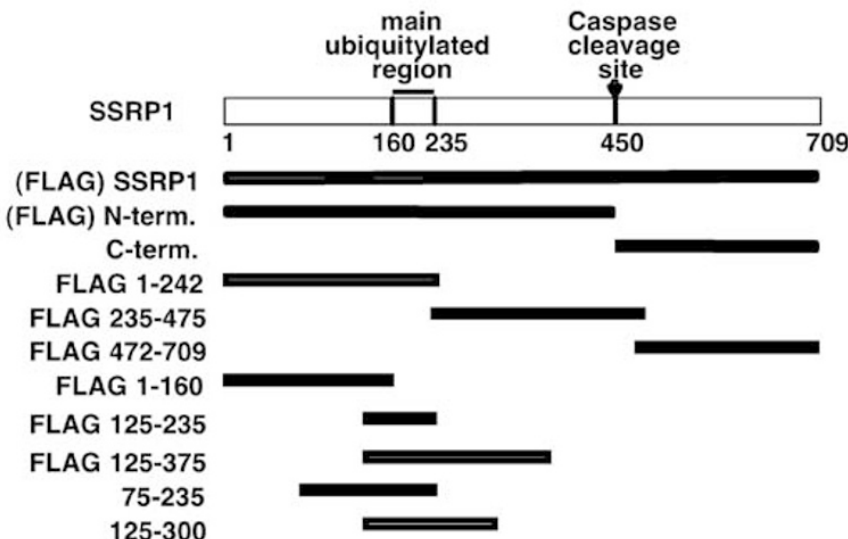

Stabilization by proteasome inhibitors

Evidence

-
+
-
+
+
-
+
+
+
+

Endo/Exo
Endo/Exo
Endo
Exo
Exo
Exo
Exo
Exo
Exo
Exo
Exo

In vivo Ubiquitylation

(Exo)

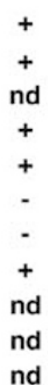

Figure 8 Ubiquitylation of SSRP1 fragments correlates with their stabilization by protease inhibitors. (a) The SSRP1 1-242 and 235-475 fragments but not the 472709 fragment are stabilized by MG132 and ubiquitylated. H1299 cells were transfected as indicated, treated or not with MG132 and processed as in Figure 7a. (b) In the region encompassing amino acid 1-242 of SSRP1, ubiquitylation occurs mainly between aa 160 and 235. H1299 cells were transfected as indicated, treated with MG132 and processed as in Figure 7a. (c) Stabilization of SSRP1 fragments by proteasome inhibitors. H1299 cells were transfected with various SSRP1 constructs (FLAGtagged or not) for $36 \mathrm{~h}$, treated with either $10 \mu \mathrm{M} \mathrm{MG} 132$ or $50 \mu \mathrm{M}$ ALLN for $16 \mathrm{~h}$ and $10 \mu \mathrm{g}$ of total proteins analyzed by immunoblot. FLAG-tagged and untagged fragments were detected as indicated. (d) Summary of the stabilization and ubiquitylation assays. SSRP1 constructs used in the study are shown under the SSRP1 schematic, along with the main $\mathrm{N}$-terminal ubiquitylated region and the caspase-cleavage site. Numbers correspond to amino-acid positions. Endo and exo, endogenous and exogenous protein/fragment; nd, not determined. (FLAG), endogenous and FLAG-tagged exogenous proteins have been tested

efficiently blocked SSRP1 cleavage (Figure 3a). Additionally, SSRP1 cleavage was more sensitive to caspase inhibitors than PARP cleavage (Figure 3a), suggesting that, in contrast with PARP, which can be cleaved by multiple caspases, ${ }^{25}$ SSRP1 is cleaved by caspase 3 and/or 7. Consistently, caspases 3 and 7 cleaved SSRP1 in vitro (Figure 4b).
Finally, in contrast with DNA-PKcs and PARP, SSRP1 was not cleaved in apoptotic MCF7, a cell line devoid of caspase 3 and caspase 7 activities (Figure $3 b$ and Supplementary Figure 2a). ${ }^{25}$

$\mathrm{DQHD}_{450}$ was identified as the caspase cleavage motif since the D450A mutation prevents SSRP1 cleavage in vitro 
and in cells (Figure 4b and c). This motif, strictly conserved among the vertebrates sequences analyzed, appears to be a novel caspase cleavage site since it is not present in the other 280 caspase substrates reviewed by Fischer et al. ${ }^{27}$ Interestingly, it is closer to the caspase 3 consensus DEVD in invertebrates (except insects) and plants (Figure 4a), suggesting that the apoptotic cleavage of SSRP1 is an evolutionary conserved event. Intriguingly, the two cleavage products of human SSRP1 resemble the yeast dipartite SSRP1 orthologs, Pob3 and Nhp6 (Figure 1c), ${ }^{18}$ suggesting that SSRP1 is structured into two major functional domains.

\section{Apoptotic cleavage of SSRP1 alters its association with chromatin}

In vitro studies have shown that mammalian SSRP1 can bind directly to naked DNA through the C-terminal HMG-1 domain. ${ }^{17,22}$ However, human SSRP1 is unable to bind mononucleosomes by itself and requires interaction with Spt $16,{ }^{6}$ which occurs via the SSRP1 N-terminal. ${ }^{13}$ These in vitro data suggest that the N-terminal part of SSRP1 is critical for its interaction with nucleosomes. As apoptotic cleavage of SSRP1 generates two similar $\mathrm{N}$ - and C-terminal fragments, it was possible to directly test this hypothesis in vivo. Chromatin fractionation assays coupled with gel filtration revealed that the C-terminal part of SSRP1 does not tightly associate with chromatin after cleavage. In contrast, the Spt16-interacting $\mathrm{N}$-terminal fragment remains bound to chromatin, confirming the published in vitro data. ${ }^{7,14}$ Interestingly, several lines of evidence suggest that the association of the truncated FACT complex with chromatin is stronger than intact FACT (Figure $5 \mathrm{a}$ and $\mathrm{b}$ ), which might enhance its effect as an irreversible, dominant negative form (see below).

\section{Functional significance of the cleavage of SSRP1 during apoptosis}

SSRP1 is an essential gene in mouse as SSRP1 knockout mice die at early embryonic stages. ${ }^{31}$ In yeast, Pob3, the $\mathrm{N}$-terminal counterpart of SSRP1, is also strictly required, as Pob3-null strains are not viable. ${ }^{9}$ More precisely, as a subunit of FACT, SSRP1 appears to be critical for transcription in a wide variety of organisms, from yeast to mammals. ${ }^{7}$ FACT is also involved in replication in yeast ${ }^{9}$ and xenopus. ${ }^{11}$ Furthermore, SSRP1 may function in more specific pathways as a coactivator for SRF and p63. ${ }^{20,21}$ Interestingly, the FACT homolog in yeast is composed of three proteins: Spt16 and Pob3 form a stable complex whereas Nhp6, which corresponds to the SSRP1 HMG domain (Figure 1c), forms a bridge between nucleosomes and Spt16/Pob3. ${ }^{10}$ Nhp6 appears to be critical for yFACT function, as Nhp6-null or mutant strains display severely reduced growth, sensitivity to 6-Azauracil (6-AU) and defects in activation of transcription at many loci. ${ }^{10,18}$ These published data confirm the vital role of SSRP1. Based on this information, inactivation of SSRP1 in the early stages of apoptosis likely impairs transcription and replication processes, accelerating the cell death. Furthermore, our subcellular localization study suggests that after cleavage, the SSRP1 N-terminal fragment remains asso- ciated with Spt16 and forms a truncated FACT complex still bound to chromatin. Whether FACT retains some activity in the absence of the SSRP1 C-terminal HMG domain has not been experimentally tested, but based on yeast data showing the importance of Nhp6 in the reorganization of nucleosomes $^{32}$ and the severity of the Nhp6-null phenotypes, ${ }^{10}$ it is likely that the functions of the human truncated FACT are largely compromised.

\section{Coupling caspase cleavage and ubiquitin- mediated degradation}

Proteasome inhibitors have emerged recently as potent apoptosis inducers. ${ }^{26}$ In our study, they also stabilized the SSRP1 N-terminal apoptotic fragment in U2OS and H1299. Further analyses revealed that this fragment is ubiquitylated in cells, demonstrating that the apoptotic $\mathrm{N}$-terminal product of SSRP1 is degraded through the ubiquitin-proteasome pathway. Ubiquitylation mainly occurred between aa 160 and 235 , although specific target lysines and the E3 ubiquitin ligase for SSRP1 remain to be identified.

Our observation that SSRP1 apoptotic cleavage is coupled with proteasomal degradation appears to be a phenomenon common to several proteins, such as Drosophila Diap1, ${ }^{33}$ mammalian $\mid \kappa \mathrm{B} \alpha^{34}$ and the potent proapototic PAK-2 kinase. ${ }^{35}$ This coupling of degradation pathways could serve several functions including regulation of apoptotic cell death. Since many proteins involved in apoptosis are activated by caspase cleavage, ${ }^{35}$ degradation of the resulting pro- or antiapoptotic fragments by the ubiquitin-proteasome pathway may add an additional level of regulation for decision making between survival and cell death. For instance, apoptotic cleavage might not completely inhibit SSRP1 activity as the $\mathrm{N}$-terminal fragment probably still forms with Spt16 a chromatin-bound, truncated FACT complex. This hypothesis is supported by yeast studies in which the Spt16-Pob3 complex appears to retain some residual activity in the absence of Nhp6, as the Nhp6-null phenotype is severe but not lethal. ${ }^{18}$ Therefore, degradation of the SSRP1 N-terminal fragment may secure the complete inactivation of FACT during apoptosis, further compromising the viability of the cell during the early stages of apoptosis.

Degradation of the SSRP1 N-terminal cleavage fragment might also prevent its release into the blood and the subsequent generation of autoantibodies. Consistent with this idea is the fact that autoantibodies against SSRP1 have been detected in sera of patients with Systemic Lupus Erythematus, ${ }^{36}$ an autoimmune disease tightly linked to apoptosis. ${ }^{36}$ This suggests a defect in the SSRP1 N-terminal fragment degradation, perhaps similar to what we observed in the Tera-2 cell line.

\section{Does SSRP1 ubiquitylation have other roles?}

SSRP1 poly-ubiquitylation occurs through a lysine 48 linkage, a feature typical of proteasomal degradation targeting. However, the full-length protein is not stabilized by proteasome inhibitors suggesting that, similar to histone $\mathrm{H} 2 \mathrm{~A}$, ubiquitylation of SSRP1 may play a signaling role. Consistent 
with this idea, the 19S proteasome subunit, which forms the 'lids' of the $26 \mathrm{~S}$ proteasome, appears to be involved in transcription elongation independently of its function in proteasomal degradation. ${ }^{37}$ In yeast, one of its components, called Sug1, genetically and physically interacts with Spt16, the heterodimeric partner of SSRP1. ${ }^{38,39}$ As the 19 S subunit is thought to bind the ubiquitin chain of targeted proteins, ${ }^{40}$ it raises the possibility that its recruitment to actively transcribed chromatin is mediated by FACT through the ubiquitylation of SSRP1 in a similar way that ubiquitylation of elongating RNA pol II allows the recruitment of diverse elongation factors. ${ }^{1}$ This poses several questions about the regulation of SSRP1 ubiquitylation: is it constitutive or does it happen upon activation of the transcriptional machinery? Also, does ubiquitylation of SSRP1 affects its interaction with Spt16?

In conclusion, at least 280 proteins are targeted by caspases during apoptosis. Cleavage inactivates or activates the substrate, accelerating the cell death. In this regard, the discovery that SSRP1 is an apoptotic target can be explained by its crucial role in critical cellular processes like transcription and replication. However, our study adds a new layer of complexity by showing that, depending of the cell line, one of the SSRP1 apoptotic fragments is further targeted to and degraded by the proteasome. Further studies will be necessary to fully understand the significance of this coupled pathway.

\section{Materials and Methods}

\section{Cell culture}

H1299, HEK293, Tera-2, MCF-7 and U2OS cells were cultured in DMEM (GIBCO-BRL) with $10 \%$ fetal bovine serum and penicillin/streptomycin on plate at $37^{\circ} \mathrm{C}$ in $5 \% \mathrm{CO}_{2}$.

\section{Antibodies and reagents}

The following antibodies were used: mouse monoclonal tubulin- $\alpha$ and FLAG M2 (Sigma), DNA-PKcs Ab-4 and p21 Ab11 (Neomarker), rabbit polyclonal histone H3 FL-136 and goat polyclonal PARP N20 (detecting the full-length protein and the $29 \mathrm{kDa}$ apoptotic fragment, Santa Cruz) and rabbit polyclonal PARP Asp214 (detecting the $89 \mathrm{kDa}$ apoptotic fragment, Cell Signaling). Rabbit polyclonal SSRP1 and Spt16 antibodies have been described. ${ }^{13,14}$ Mouse monoclonal SSRP1 antibodies 1G6 and 4F7 were generated by Zymed Laboratories (Invitrogen) using bacterially expressed his-tagged SSRP1 in denatured form. SSRP1 antibodies were affinitypurified using the same antigen crosslinked to $\mathrm{CnBr}$-activated sepharose 4B beads (Amersham Biosciences, Sweden). We also used Puromycin and DRB (Sigma), CHX (ICN Biochemicals), MG132 (Peptide Institute Inc. Japan), ALLN (Calbiochem), TNF- $\alpha$ (Peprotech Inc.), caspase inhibitors (Z-VAD-FMK and Z-DEVD-FMK) (BD Pharmingen) and caspase 3 (Biovision).

\section{Constructs}

PCDNA3-2xFLAG -SSRP1 and SSRP1 1-242 have been described. ${ }^{21}$ Three other SSRP1 fragments (125-235, 235-475 and 472-709) were subcloned in the same vector. Two fragments (aa 75-235 and 125-300) were subcloned in pcDNA3.1 with no tag. A stop codon was generated in pcDNA3-2xFLAG-SSRP1 by site-directed mutagenesis (QuickChange kit,
Stratagene), allowing the expression of the 1-160 fragment. The same kit was used to generate a $D \rightarrow A$ mutation at position 450 in the same vector and in pet24a-hisSSRP1. FLAG-caspase 7 was subcloned from pcDNA3 to pet24a vector. The baculovirus expressing FLAG-Spt16 has been described. ${ }^{6}$

\section{Induction of apotosis and immunoblots}

Cells were either irradiated with UVC or treated with chemicals added in the culture medium (DRB $100 \mu \mathrm{M}, \mathrm{MG} 13210 \mu \mathrm{M}$, ALLN $50 \mu \mathrm{M}$ or TNF- $\alpha$ $30 \mathrm{ng} / \mathrm{ml}+\mathrm{CHX} 10 \mu \mathrm{g} / \mathrm{ml}$ ) and harvested at different times post-treatment as indicated. Cells were scrapped in the culture medium, washed once in PBS and lysed in $50 \mathrm{mM}$ Tris- $\mathrm{HCl}, \mathrm{pH} 8.0,150 \mathrm{mM} \mathrm{NaCl}, 5 \mathrm{mM}$ EDTA, $0.5 \%$ NP40. Same amounts of WCL (as determined by the Bradford method) were loaded onto an SDS-PAGE, electrophoresed and transferred onto a PVDF membrane. Blots were probed with specific primary and HRP-conjugated secondary antibodies, and proteins detected using ECL (Bio-Rad). For detection of multiple proteins on the same blot, the membrane was stripped for $30 \mathrm{~min}$ at $50^{\circ} \mathrm{C}$ in $65 \mathrm{mM}$ Tris- $\mathrm{HCl} \mathrm{pH} \mathrm{6.8,}$ $2 \%$ SDS, $100 \mathrm{mM} \beta$-mercaptoethanol and reprobed. In apoptosis inhibition assays, cells were preincubated for $30 \mathrm{~min}$ with caspase inhibitors prior to apoptosis induction.

\section{In vitro caspase cleavage assay}

Specific activity for caspase 3 (purified) and caspase 7 (bacterial lysate) were assessed using the Apo-ONE Homogeneous caspase 3/7 assay kit (Promega). One or two units were incubated with $100 \mathrm{ng}$ of purified his-SSRP1, his-SSRP1 D450A or FLAG-Spt16 for $4 \mathrm{~h}$ at $37^{\circ} \mathrm{C}$ in $30 \mu \mathrm{l}$ of cleavage buffer (20 mM Tris- $\mathrm{HCl}$ pH 7.5, $10 \mathrm{mM}$ DTT, $0.1 \mathrm{mM}$ EDTA). Reactions were stopped by addition of SDS sample buffer and analyzed by immunoblot.

\section{Chromatin fractionation and gel filtration}

Subconfluent Tera-2 cells in $150 \mathrm{~mm}$ plates were treated with UVC $(100 \mathrm{~J} /$ $\left.\mathrm{m}^{2}\right)$ for $24 \mathrm{~h}$, harvested and lysed in $400 \mu \mathrm{l}$ RIPA buffer $(50 \mathrm{mM}$ Tris- $\mathrm{HCl}$ $\mathrm{pH} 7.5,150 \mathrm{mM} \mathrm{NaCl}, 1 \%$ sodium deoxycholate, $1 \% \mathrm{NP}-40,0.1 \%$ SDS, $1 \mathrm{mM}$ PMSF, $1 \mathrm{mM}$ pepstatin A) for $10 \mathrm{~min}$. The WCL was centrifuged for $5 \mathrm{~min}\left(16000 \times \mathrm{g}, 4^{\circ} \mathrm{C}\right)$ and the resulting supernatant (soluble fraction) was further centrifuged for $20 \mathrm{~min}$ to eliminate any trace of insoluble material. The pellet was washed twice with RIPA buffer, resuspended in $300 \mu \mathrm{l}$ RIPA buffer and sonicated using a Sonic Dismembrator 60 (Fisher Scientific), $3 \times 10 \mathrm{~s}$ setting max. After centrifugation $(20 \mathrm{~min}$ at $16000 \times g$ ), the supernatant (resolubilized chromatin fraction) was collected. Fractions were analyzed directly by immunoblot, whereas $100 \mu \mathrm{l}$ of chromatin fractions from both untreated and UVC-treated cells were further passed through a $3.2 \mathrm{ml}$ superose 6 column (Amersham Bioscience) equilibrated with RIPA buffer (flow rate $50 \mu \mathrm{l} / \mathrm{min}$ ). In all, 36 fractions ( $50 \mu \mathrm{l}$ each) were collected and one out of two analyzed by immunoblot using the indicated antibodies.

\section{In vivo ubiquitylation assay and transfection}

$\mathrm{H} 1299$ cells in $100 \mathrm{~mm}$ plates were cotransfected with $2 \mu \mathrm{g}$ his-ubiquitin (or empty vector or his-Ubiquitin K48R) and $2 \mu \mathrm{g}$ various FLAG-tagged SSRP1 constructs using lipofectin (Invitrogen). Cells were treated with MG132 $(10 \mu \mathrm{M}) 32 \mathrm{~h}$ after transfection, harvested $16 \mathrm{~h}$ later (or otherwise indicated) and split into two aliquots, one for immunoblots and the other for pull-down of ubiquitylated proteins using Ni-NTA beads (Qiagen). Proteins 
eluted from the beads were analyzed by immunoblot and SSRP1 was detected using the FLAG antibody.

\section{FACS analysis}

U2OS cells were transfected with FLAG-SSRP1 or SSRP1 D450A and treated $32 \mathrm{~h}$ later with TNF- $\alpha+\mathrm{CHX}$ for 9 or $16 \mathrm{~h}$. After harvest and PBS washes, $10^{5}$ cells were stained using the Annexin V-FITC Apoptosis Detection Kit I (BD Pharmingen) following the recommendations of the manufacturer. $1.5 \times 10^{4}$ cells were counted using a Becton Dickinson FACScan flow cytometer and analyzed using the CELLQuest software.

\section{Acknowledgements}

We thank Yi Sun from the University of Michigan for the generous gift of the PcDNA3-FLAG-caspase 7 construct, Mushui Dai for assistance with FACS analysis and the MDM2 construct, Yetao Jin for the MDM2 data, Mary MacPartlin, Anuradha Kumari and Stephen Malkoski for proofreading the manuscript and David Keller for his invaluable help during the initial phase of the project. This work is supported by $\mathrm{NCl}$ Grants CA93614, CA095441 and CA 079721 to HL.

\section{References}

1. Shilatifard A, Conaway RC, Conaway JW (2003) The RNA polymerase II elongation complex. Annu. Rev. Biochem. 72: 693-715.

2. Gerbi SA, Bielinsky AK (2002) DNA replication and chromatin. Curr. Opin Genet. Dev. 12: 243-248.

3. Gontijo AM, Green CM, Almouzni G (2003) Repairing DNA damage in chromatin. Biochimie. 85: 1133-1147.

4. Widom J (1997) Chromatin: the nucleosome unwrapped. Curr. Biol. 7: R653-R655.

5. Orphanides G, LeRoy G, Chang CH, Luse DS, Reinberg D (1998) FACT, a factor that facilitates transcript elongation through nucleosomes. Cell 92 $105-116$.

6. Belotserkovskaya R, Oh S, Bondarenko VA, Orphanides G, Studitsky VM, Reinberg D (2003) FACT facilitates transcription-dependent nucleosome alteration. Science 301: 1090-1093.

7. Belotserkovskaya R, Reinberg D (2004) Facts about FACT and transcript elongation through chromatin. Curr. Opin. Genet. Dev. 14: 139-146.

8. Sif S (2004) ATP-dependent nucleosome remodeling complexes: enzymes tailored to deal with chromatin. J. Cell Biochem. 91: 1087-1098.

9. Wittmeyer J, Formosa T (1997) The Saccharomyces cerevisiae DNA polymerase alpha catalytic subunit interacts with $\mathrm{Cdc} 68 / \mathrm{Spt16}$ and with Pob3, a protein similar to an HMG1-like protein. Mol. Cell. Biol. 17: 4178-4190.

10. Formosa $T$ (2003) Changing the DNA landscape: putting a SPN on chromatin Curr. Top. Microbiol. Immunol. 274: 171-201.

11. Okuhara K, Ohta K, Seo H, Shioda M, Yamada T, Tanaka Y, Dohmae N, Seyama Y, Shibata T, Murofushi H (1999) A DNA unwinding factor involved in DNA replication in cell-free extracts of Xenopus eggs. Curr. Biol. 9: 341-350.

12. Shirakata M, Huppi K, Usuda S, Okazaki K, Yoshida K, Sakano H (1991) HMG1-related DNA-binding protein isolated with V-(D)-J recombination signal probes. Mol. Cell. Biol. 11: 4528-4536.

13. Keller DM, Lu H (2002) p53 serine 392 phosphorylation increases after UV through induction of the assembly of the CK2.hSPT16.SSRP1 complex. J. Biol. Chem. 277: 50206-50213.

14. Keller DM, Zeng $X$, Wang $Y$, Zhang $\mathrm{QH}$, Kapoor M, Shu H, Goodman $\mathrm{R}$ Lozano G, Zhao Y, Lu H (2001) A DNA damage-induced p53 serine 392 kinase complex contains CK2, hSpt16, and SSRP1. Mol. Cell 7: 283-292.

15. Malone EA, Clark CD, Chiang A, Winston F (1991) Mutations in SPT16/CDC68 suppress cis- and trans-acting mutations that affect promoter function in Saccharomyces cerevisiae. Mol. Cell. Biol. 11: 5710-5717.
16. Bruhn SL, Pil PM, Essigmann JM, Housman DE, Lippard SJ (1992) Isolation and characterization of human cDNA clones encoding a high mobility group box protein that recognizes structural distortions to DNA caused by binding of the anticancer agent cisplatin. Proc. Natl. Acad. Sci. USA 89: 2307-2311.

17. Gariglio M, Ying GG, Hertel L, Gaboli M, Clerc RG, Landolfo S (1997) The high-mobility group protein T160 binds to both linear and cruciform DNA and mediates DNA bending as determined by ring closure. Exp. Cell. Res. 236: 472-481.

18. Brewster NK, Johnston GC, Singer RA (2001) A bipartite yeast SSRP1 analog comprised of Pob3 and Nhp6 proteins modulates transcription. Mol. Cell. Biol. 21: 3491-3502.

19. Dyer MA, Hayes PJ, Baron MH (1998) The HMG domain protein SSRP1/ PREIIBF is involved in activation of the human embryonic beta-like globin gene. Mol. Cell. Biol. 18: 2617-2628.

20. Spencer JA, Baron MH, Olson EN (1999) Cooperative transcriptional activation by serum response factor and the high mobility group protein SSRP1. J. Biol. Chem. 274: 15686-15693.

21. Zeng SX, Dai MS, Keller DM, Lu H (2004) SSRP1 functions as a co-activator of the transcriptional activator p63. EMBO J. 23: 1679.

22. Li Y, Keller DM, Scott JD, Lu H (2005) CK2 phosphorylates SSRP1 and inhibits its DNA-binding activity. J. Biol. Chem. 280: 11869-11875.

23. Krohn NM, Stemmer C, Fojan P, Grimm R, Grasser KD (2003) Protein kinase CK2 phosphorylates the high mobility group domain protein SSRP1, inducing the recognition of UV-damaged DNA. J. Biol. Chem. 278: 12710-12715.

24. Zeng X, Keller D, Wu L, Lu H (2000) UV but not gamma irradiation accelerates p53-induced apoptosis of teratocarcinoma cells by repressing MDM2 transcription. Cancer Res. 60: 6184-6188.

25. Janicke RU, Ng P, Sprengart ML, Porter AG (1998) Caspase-3 is required for alpha-fodrin cleavage but dispensable for cleavage of other death substrates in apoptosis. J. Biol. Chem. 273: 15540-15545.

26. Zhu H, Zhang L, Dong F, Guo W, Wu S, Teraishi F, Davis JJ, Chiao PJ, Fang B (2005) Bik/NBK accumulation correlates with apoptosis-induction by bortezomib (PS-341, Velcade) and other proteasome inhibitors. Oncogene 24: 4993-4999.

27. Fischer U, Janicke RU, Schulze-Osthoff K (2003) Many cuts to ruin: a comprehensive update of caspase substrates. Cell Death Differ. 10: 76-100.

28. Thornberry NA, Rano TA, Peterson EP, Rasper DM, Timkey T, Garcia-Calvo M, Houtzager VM, Nordstrom PA, Roy S, Vaillancourt JP, Chapman KT, Nicholson DW (1997) A combinatorial approach defines specificities of members of the caspase family and granzyme B. Functional relationships established for key mediators of apoptosis. J. Biol. Chem. 272: 17907-17911.

29. Norbury CJ, Zhivotovsky B (2004) DNA damage-induced apoptosis. Oncogene 23: 2797-2808.

30. Nicholson DW, Ali A, Thornberry NA, Vaillancourt JP, Ding CK, Gallant M, Gareau Y, Griffin PR, Labelle M, Lazebnik YA, Munday NA, Raju SM, Smulson ME, Yamin T, Yu VL, Miller DK (1995) Identification and inhibition of the ICE/CED-3 protease necessary for mammalian apoptosis. Nature 376 : 37-43.

31. Cao S, Bendall H, Hicks GG, Nashabi A, Sakano H, Shinkai Y, Gariglio M, Oltz EM, Ruley HE (2003) The high-mobility-group box protein SSRP1/T160 is essential for cell viability in day 3.5 mouse embryos. Mol. Cell. Biol. 23: 5301-5307.

32. Ruone S, Rhoades AR, Formosa T (2003) Multiple Nhp6 molecules are required to recruit Spt16-Pob3 to form yFACT complexes and to reorganize nucleosomes. J. Biol. Chem. 278: 45288-45295.

33. Ditzel M, Wilson R, Tenev T, Zachariou A, Paul A, Deas E, Meier P (2003) Degradation of DIAP1 by the N-end rule pathway is essential for regulating apoptosis. Nat. Cell Biol. 5: 467-473.

34. Rathore N, Matta H, Chaudhary PM (2004) An evolutionary conserved pathway of nuclear factor-kappaB activation involving caspase-mediated cleavage and $\mathrm{N}$-end rule pathway-mediated degradation of IkappaBalpha. J. Biol. Chem. 279: 39358-39365

35. Jakobi R, McCarthy CC, Koeppel MA, Stringer DK (2003) Caspase-activated PAK-2 is regulated by subcellular targeting and proteasomal degradation. J. Biol. Chem. 278: 38675-38685.

36. Fineschi S, Borghi MO, Riboldi P, Gariglio M, Buzio C, Landolfo S, Cebecauer L, Tuchynova A, Rovensky J, Meroni PL (2004) Prevalence of autoantibodies against structure specific recognition protein 1 in systemic lupus erythematosus. Lupus 13: 463-468. 
37. Gonzalez F, Delahodde A, Kodadek T, Johnston SA (2002) Recruitment of a 195 proteasome subcomplex to an activated promoter. Science 296 : 548-550.

38. Xu Q, Singer RA, Johnston GC (1995) Sug1 modulates yeast transcription activation by Cdc68. Mol. Cell. Biol. 15: 6025-6035.
39. Sun L, Johnston SA, Kodadek T (2002) Physical association of the APIS complex and general transcription factors. Biochem. Biophys. Res. Commun. 296: 991-999.

40. Baumeister W, Walz J, Zuhl F, Seemuller E (1998) The proteasome: paradigm of a self-compartmentalizing protease. Cell 92: 367-380.

Supplementary information accompanies the paper on Cell Death and Differentiation website (http:// www.nature.com/cdd). 